\title{
INFLUENCE OF ELECTRON BEAM TREATMENT ON THE CRYSTALLIZATION AND THERMAL STABILITY OF LDPE/EPDM BLENDS
}

\author{
${ }^{2}$ Bhuwanesh Kumar Sharma, ${ }^{1}$ Subhendu Ray Chowdhury, \\ ${ }^{2}$ P.A. Mahanwar and ${ }^{1}$ K.S.S. Sarma \\ ${ }^{1}$ Radiation Technology Development Division, \\ Bhabha Atomic Research Centre, Trombay, Mumbai-400 085, India \\ ${ }^{2}$ Institute of Chemical Technology, Matunga, Mumbai, India
}

Received 2014-08-31; Revised 2014-09-18; Accepted 2014-09-23

\begin{abstract}
The effect of blend composition and Electron Beam (EB) irradiation on the crystallization and thermal behavior of Low Density Polyethylene (LDPE)/Ethylene-Propylene-Diene elastomer (EPDM) blends had been studied. Melting temperatures were found to remain unchanged upon variation of blend composition as well as irradiation dose. But the degree of crystallinity and $T_{c}$ (crystallization temperature) were decreased with increase in EPDM content and EB dose. On the other hand, thermal stability (in terms of onset temperature and degradation temperature) and activation energy were increased with increase in EPDM content and irradiation dose. But the speed of degradation slowed down with increasing EPDM content and EB dose. Interestingly, once Trimethylolpropane Triacrylate (TMPTA) and Triallyl Cynuerate (TAC) were incorporated into the blends, the degrees of change of these properties were more in same direction upon irradiation. At higher irradiation dose properties were demoted due to chain scission.
\end{abstract}

Keywords: Low Density Polyethylene (LDPE), Ethylene-Propylene-Diene Elastomer (EPDM), Crystallinity, Degradation, EB Irradiation, TMPTA and TAC

\section{INTRODUCTION}

Radiation cross linking becomes an effective tool to improve properties of polymeric materials (Ray Chowdhury and Sabharwal, 2011; Zaharescu et al., 1999). Radiation processing of polymers starts with gamma irradiations in industry and academia (Cleland et al., 2003; Machi, 1995). Gamma radiation plays a significant role in polymer crosslinking and chain scission to alter properties. Many reports on gamma radiation processing are available with successful and useful outcomes (Ray Chowdhury et al., 2012a). However, now-a-days fascination is increasing towards electron beam irradiation due to some limitations of gamma irradiation instead of the later having less initial investment and high penetration power due to electromagnetic nature (Ray Chowdhury et al., 2012b; Magida, 2012). The limitations of gamma irradiation are difficulties of large scale processing, time consumption, handling of isotopes, transportation, safety of worker (Sam et al., 2012; Jamal et al., 2011). Electron beam irradiation affects mechanical, chemical, electrical and thermal properties of polymers as gamma radiation does. Upon irradiation polymer generates macro radicals, which combine and form inter chain or intra chain network (Mohamed et al., 2012; Abdel-Aziz et al., 1992). Such compact crosslinked network with and without involvement of crosslinker or chain scission can alter Trombay, Mumbai-400 085, India, Tel.: +91-22-27887347 
the above mentioned properties (Hung et al., 2004; Wang et al., 2009).

Radiation processing changes the thermal stability and crystallization behavior i.e., associated properties of polymers significantly (Vranjesn and Rek, 2007; Chattopadhyay et al., 2001). Both are important from application point of view. There are many reports on radiation processing and properties of LDPE, HDPE, PP, EP, SEB, PDMS. Among the polyolefins, Low Density Polyethylene (LDPE) and Linear Low Density Polyethylene (LLDPE) are widely used in the packaging and consumer industry because of their advantages like excellent mechanical properties, thermal stability, good environmental stress crack resistance, flexibility, excellent dielectric properties, availability and low cost (Maziyar et al., 2012; Santra et al., 1993). Most of the synthetic rubbers (styrene butadiene rubber, chloroprene rubber) have been replaced by LDPE. Crosslinked LDPEs are widely used in heat shrinkable materials, wire and cables and construction (Ray Chowdhury et al., 2000; 2012b). On the other hand, Ethylene Propylene Diene (EPDM) has attractive crosslinking ability, heat and ozone resistance properties and dynamic damping properties (Sen Majumder and Bhowmick, 2000).

By judicial selection of properties of LDPE and EPDM, scientists have made blends of two, to get selected combination of properties. That is why, LDPEEPDM blends have got their application in automobile, wire and cable insulation and construction applications (Morteza et al., 2009; Senna et al., 2007). Needless to say that the use of radiation can be a good option to improve the properties of LDPE-EPDM blends.

To study different aspects, such as mechanical, thermal, rheological and morphological properties, PE/EPDM blends have been prepared and investigated (Airinei et al., 2013; Sadek et al., 2003; Nouri and Mehrabzadeh, 1996; Mukhopadhyay and Das, 1990).

Some studies on radiation processing (gamma) of polyolefins/EPDM have been reported (Zaharescu et al., 1999; Abdel-Aziz et al., 1992; Rizk et al., 2009). So far our knowledge is concern there is no reported literature on the influence of EB on crystallization and thermal stability of LDPE/EPDM blends.

Thus, our present work represents the effect of EB crosslinking on crystallization properties and thermal stability of LDPE/EPDM blends. We have also used polyfunctional monomers such as Trimethylolpropane Triacrylate (TMPTA) and Triallyl Cynuerate (TAC) as cross linking agent to improve the properties in a higher degree.

\section{EXPERIMENTAL}

\subsection{Materials}

Low Density Polyethylene (LDPE; MFI 4 gm/10 min, density of $0.922 \mathrm{gm} / \mathrm{cc}$ ) in form of pellets are supplied by Reliance Petrochemicals. Ethylene Propylene Diene elastomer, KELTAN (EPDM; propylene content $=55 \%$ with $5.5 \%$ of ENB, MFI10 $\mathrm{gm} / 10 \mathrm{~min}$ and density of $0.88 \mathrm{gm} / \mathrm{cc}$ ) was procured from DSM Netherland. The polyfunctional monomers (crosslinking agent) like Trimethylolpropane Triacrylate (TMPTA) and Triallyl Cynuerate (TAC) were procured from Sigma Aldrich (India).

\subsection{Preparation of Blends}

LDPE was blended with EPDM in different compositions using twin screw extruder at the temperature profile of $120: 140: 160: 180^{\circ} \mathrm{C}$ at $80 \mathrm{rpm}$. Blends were prepared in various proportions with and without crosslinker as in Table 1. Cross linkers (TMPTA and TAC) were used in 1 phr. For study purpose dumble shaped samples were prepared by injection molding at $180^{\circ} \mathrm{C}$. The codes of the samples are in Table $\mathbf{1}$. Mentioning 'TMPTA' or 'TAC' in the sample codes, implies that $1 \mathrm{phr}$ (w.r.t total mass of blend) of TMPTA or TAC is incorporated in the formulation.

\subsection{Electron Beam Irradiation of Test Specimens}

The injection molded specimens were irradiated by high energy electron beam in an inert environment using $2 \mathrm{MeV}, 20 \mathrm{~kW}$ EB accelerator (Model ILU-6) under forced air cooling at a radiation dose of 40, 80 and 120 kGy (kilo Grey). Only one side of the sample was exposed to irradiation, as the thickness of the sheets was $2 \mathrm{~mm}$, which was thin enough for penetration of the electron beam of $2 \mathrm{MeV}$ energy.

The distance of the sample from the scan horn was 20 $\mathrm{cm}$ and the conveyer speed was set at $0.94 \mathrm{~m} / \mathrm{min}$. The dose rate was $10 \mathrm{kGy} /$ pass and beam current was $1 \mathrm{~mA}$.

\subsection{Characterization}

\subsubsection{Determination of Gel Fraction (\% Gel Content)}

Gel fractions were measured by solvent extraction technique using xylene as solvent. The samples were extracted in hot xylene for $48 \mathrm{~h}$ at $110^{\circ} \mathrm{C}$. Extracted samples were dried in a vacuum oven at $80^{\circ} \mathrm{C}$ till constant mass. The gel content (\% gel fraction) was determined using the following formula Equation 1: 
Table 1. Blend compositions

\begin{tabular}{lrrrrr}
\hline Samples & 1 & 2 & 3 & 4 & 5 \\
\hline LDPE & 100 & 80 & 50 & 20 & 0 \\
EPDM & 0 & 20 & 50 & 80 & 100 \\
Sample code & L 100 & LE 82 & LE55 & LE 28 & E 100 \\
\hline
\end{tabular}

where, 'L' stands for LDPE and 'E' for EPDM, 'TMPTA'-Trimethylol propane triacrylate, 'TAC'- Triallyl cyanurate. If TMPTA and TAC are mentioned in sample code that means $1 \mathrm{phr}$ (parts per hundred) TMPTA or TAC has been added respectively

$(\%)$ Gel content $=\frac{\text { Mass after extraction }}{\text { Mass before extraction }} \times 100$

\subsubsection{Differential Scanning Calorimetry (DSC)}

DSC analysis was carried out at heating and cooling rate of $10^{\circ} \mathrm{C} \mathrm{min}^{-1}$ in $\mathrm{N}_{2}$ atmosphere using Perkin-Elmer DSC thermal analyzer from room temperature to $160^{\circ} \mathrm{C}$. The samples were heated at $10^{\circ} \mathrm{C} \min ^{-1}$ up to $160^{\circ} \mathrm{C}$ and held for $5 \mathrm{~min}$ at $160^{\circ} \mathrm{C}$ (molten stage). Then samples were cooled at the same speed up to room temperature. $T_{m}$ (melting temperature), $\Delta H_{m}$ (heat of fusion) and $\% \mathrm{C}$ (\% crystallinity) are calculated from the melting (heating) curve (endothermic peak). Crystallization Temperatures $\left(T_{c} s\right)$ are calculated from crystallization of cooling curve (exothermic peak). The degree of crystallinity $\left(X_{c}\right)$ is calculated from heat of fusion under melting endotherm, using following formula Equation 2:

$X_{c}=\frac{\Delta H_{m}}{\Delta H_{m} 0} \times 100$

where, $\Delta H_{m}$ is the melting enthalpy of sample and $\Delta H_{m} 0$ is the melting enthalpy of $100 \%$ crystalline sample (where $\Delta H_{m} 0$ for $100 \%$ crystalline LDPE is taken as $239 \mathrm{Jg}^{-1}$ (Morawiec et al., 2005). The melting enthalpy of $100 \%$ crystalline EPDM has been considered as the heat of fusion of $100 \%$ crystalline LDPE as hydrocarbon chain only is responsible for EPDM crystallinity (Britton et al., 1978).

\subsubsection{Thermogravimetric Analysis (TG)}

Thermogravimetric analysis (TG) of the virgin polymers, their blends with and without crosslink coagent (TMPTA and TAC) before and after electron beam irradiation were carried out using a Thermogravimetric analyzer (TG Q 100) under $N_{2}$ atmosphere at a heating rate of $10^{\circ} \mathrm{C} \mathrm{min}^{-1}$. To compare the nature of degradation of various samples, $T_{i}$ (onset), $T_{d}$ (degradation temperature), $T_{30}$ (temperature corresponding to $30 \%$ mass loss), $T_{50}$ (temperature corresponding to $50 \%$ mass loss) and $T_{90}$ (temperature corresponding to $90 \%$ mass loss) were calculated from TG graphs.

The determination of the activation energy of degradation is important parameter for evaluating the ease of thermal decomposition of polymer. In our work, the integral method of Coats and Redfern has been used to determine the activation Energy of degradation (E) (Coats and Redfern, 1964; Baloch et al., 2011). However, different investigators have been using different methods to calculate the activation energy of polymer (Flynn and Wall, 1996; Kissinger, 1957; Kayacan and Doğan, 2008). The Coats and Redfern model gives the best linear fit and also this model has been mostly and successfully used for studying the kinetics of decomposition and dehydration. This approach is applied for single TG graph. That is why this model is chosen.

\section{RESULTS AND DISCUSSION}

\subsection{Gel Fraction Analysis}

The crosslinking efficiency of LDPE, EPDM and various LDPE/EPDM blends, at various doses, in absence and presence of crosslinker, is estimated from the gel fraction determination. Results are presented in Fig. 1. Higher is the gel content greater will be the amount of crosslinking, as gel content is the measurement of amount of crosslinking (Charlesby et al., 1959; Charlesby, 1954). There is no gel formation observed for control systems. It is clear from the Fig. 1 that neat LDPE shows 50.43, 71.94 and $78.01 \%$ gel fraction at 40, 80 and $120 \mathrm{kGy}$ EB doses. On the other hand, for pure EPDM, the gel contents are $76.81,87.69$ and $92.38 \%$ at the same doses respectively. Thus it is revealed that with increase in doses the gel content i.e., crosslinking ability is increased steadily with increase in radiation doses. That proves up to $120 \mathrm{kGy}$, in both the polymers, crosslinking process dominates over the chain scission process as the gel content is the measurement of crosslinking. From the findings it is again obvious that, at a certain dose, EPDM shows higher gel fraction than LDPE and that is true for all studied 
doses. That is due to higher crosslinking ability of EPDM than LDPE (Dikland and Van Duin, 2002). The crosslinking ability of EPDM is more due to higher amorphousness and molecular structure of EPDM. So it is expected that with increase in EPDM content in blends, gel fraction will keep on increasing. That is the finding throughout the experiments.

Interestingly, as in LDPE and EPDM, the gel contents of LDPE/EPDM blends with and without crosslinker are also in increasing trend with increase in irradiation dose. In LE 82 blends without crosslinker, the percentages of gel fractions are observed to be 57.6, 76.54 and $81.7 \%$ for different electron beam doses (40, 80 and $120 \mathrm{kGy}$ ). In LE55 blends, the gel fractions are higher than that of LE 82 blends due to greater amount of EPDM content in blends. The increased gel content in LE 55 blends are 63.39, 77.00 and $85.02 \%$ at 40, 80 and $120 \mathrm{kGy}$ EB. It is seen that LE 28 blends shows significant enhancement in gel fraction compared to LE 82 and LE 55 blends. The value of gel fraction for LE28 blends are $68.86,82.35$ and $89.68 \%$ at same dose rate of 40, 80 and $120 \mathrm{kGy}$, respectively.

Further, it is noticed that the gel content i.e., crosslinking ability of blends is increased after adding TMPTA and TAC. The TMPTA and TAC containing samples exhibit higher amount of gel than without ones due to higher degree of crosslinking.

In TMPTA and TAC added LE 82 samples, gel fractions are found to be $64.54,80.93$ and $85.34 \%$ and 61.57, 78.93 and $83.67 \%$ at 40,80 and $120 \mathrm{kGy}$ respectively. The TMPTA and TAC containing LE 55 samples show 71.58, 83.92 and $90.13 \%$ and 68.54 , 80.03 and $87.66 \%$ gel fraction values at 40,80 and $120 \mathrm{kGy}$ doses.

Thus, TMPTA is found to be more efficient crosslinker than TAC for LDPE/EPDM system (Fig. 1). Both of these multifunctional monomers are three functional. Both join two polymer chains through C-C bridge formation and form three dimensional networks in a same fashion (Pyun et al., 1982). But why is this difference? According to Handlos (1979), the gel promoting efficiencies of these functional monomers depend on the initial ' $G$ ' values (crosslinking) value of monomers. In fact TMPTA possesses higher number of reactive double bonds than TAC (Waldron et al., 1985). R. Wiedenmann reports that there are so many unreacted double bonds in TAC-blended PE after irradiation (Wiedenmann, 1977). A similar trend is observed for TMPTA and TAC added LE28 samples, which exhibits
$75.58,89.19$ and $93.95 \%$ and $72.26,85.98$ and $92.03 \%$ gel content at above-mentioned doses.

\subsection{Differential Scanning Calorimetry (DSC)}

The effect of blend compositions and electron beam radiation dose on the melting temperature $\left(T_{m}\right)$, crystallization temperature $\left(T_{c}\right)$, heat of fusion $\left(\Delta H_{m}\right)$ and degree of crystallinity $\left(X_{c}\right)$ of LDPE/EPDM blends system have been analyzed by DSC. DSC curves of neat LDPE, EPDM and their blends before and after electron beam irradiation at different doses (40, 80 and $120 \mathrm{kGy}$ ) are represented in Fig. 2 to 4 . The value of melting temperature $\left(T_{m}\right)$, heat of fusion $\left(\Delta H_{m}\right)$ and degree of crystallinity $\left(X_{c}\right)$ computed from the DSC endothermic and crystallization temperature $\left(T_{c}\right)$ from exothermic curves are tabulated in Table 2. Figure 2a shows that for neat LDPE and EPDM prominent melting peaks $\left(T_{m}\right)$ appear at 110.03 and $52.62^{\circ} \mathrm{C}$ respectively. In all blends (LE 82, LE 55 and LE 28) two melting peaks corresponding to LDPE and EPDM phase have been observed.

The addition of higher amount of EPDM in LDPE causes little decrease of melting point of LDPE (Table 2). In LE 82 blend, the melting temperatures of LDPE and EPDM have been observed at 109.01 and $52.14^{\circ} \mathrm{C}$ respectively. In LE 55 blend, where both LDPE and EPDM are in equal proportions, the melting peak of LDPE shifts slightly towards lower temperature $\left(105^{\circ} \mathrm{C}\right)$ while there is no considerable change in melting temperature of EPDM which is found at $54.0^{\circ} \mathrm{C}$. LE 28 blend shows the melting peak of LDPE and EPDM at 104.22 and $51.94^{\circ} \mathrm{C}$ respectively.

The electron beam irradiation of LE 82, LE 55 and LE 28 blends by 40, 80 and $120 \mathrm{kGy}$ has not imparted considerable effect in melting temperatures of both LDPE and EPDM (Fig. 2a to 4a and Table 2). Even after incorporation of cross linking agent (TMPTA and $\mathrm{TAC}$ ), i.e., higher degree of crosslinking no change of $T_{m}$ is observed.

Figure $2 \mathbf{b}$ to $\mathbf{4 b}$ show DSC exothermic curves (cooling curve) of unirradiated and irradiated LDPE, EPDM and blends. The crystallization peak of LDPE has appeared as a sharp and narrow peak at $95.03^{\circ} \mathrm{C}\left(T_{c}\right)$. EPDM shows a blunt and somewhat wide crystallization peak at $32^{\circ} \mathrm{C}$ (Fig. 2b). It is seen that blending of EPDM with LDPE causes the shifting of crystallization temperature of LDPE to lower temperature range though for LE82 Tc does not change (Table 2). The $T_{c} s$ of LDPE and EPDM in LE 82 blends are found to be 94.68 and $50.0^{\circ} \mathrm{C}$ and LE 55 
shows the $T_{c} s$ of LDPE and EPDM at 88.03 and 43.0, while LE 28 exhibits the crystallization temperature of LDPE and EPDM at 84.12 and $36.1^{\circ} \mathrm{C}$ respectively. So it is revealed that EPDM, being in a molten state during crystallization of LDPE, does not act as nucleating agent for LDPE crystallization.

Again, interestingly it is noticed that as the LDPE content is increased in blends Tc of EPDM keeps on increasing (Tc of LE28, LE55 and LE82 are 36.1, 43.0 and $50^{\circ} \mathrm{C}$ respectively). This is due to the presence of already formed solid LDPE crystals in molten EPDM phase (Table 2), which acts as nucleating agent turning the nucleation process of EPDM heterogeneous (Ray Chowdhury and Sabharwal, 2011).

The electron beam crosslinking shows influence on the crystallization Temperature $\left(T_{c}\right)$ of the blends, which is prominent at higher doses (Table 2). For all crosslinked blends, $T_{c}$ of LDPE is decreased due to movement restriction of polymer chains engaged in network formation. Due to compact network formation crystallizing efficiencies of chains are reduced. In all blends $T_{c}$ of EPDM has a tendency to go down at high irradiation dose (Table 2). Once the EPDM content is high (LE55 and LE28) then after crosslinking $T_{c}$ of EPDM does not appear at all. As crosslinking efficiency of EPDM is high, thus at high dose, higher EPDM containing blends will show higher degree of crosslinking. That's why crystallization is very much discouraged due to higher degree of restriction of polymer chain movement.

However, the irradiation of TMPTA and TAC added blends ( $80 \mathrm{kGy}$ dose is reported here) bring the similar effect on Tc of LDPE and EPDM in all three blends (Table 2 and Fig. 2b to 4b).

Another important parameter, the heat of fusion (melting peak area) i.e., amount of crystallinity is significantly affected by blend compositions as well as radiation dose (Table 2 and Fig. 2a to 4a). Neat LDPE and EPDM exhibit heat of fusion to be 83.01 and $25.79 \mathrm{Jg}^{-1}$, consequently 34.73 and $10.79 \%$ crystallinity respectively (Table 2 ). The addition of EPDM in LDPE leads to decrease heat of fusion i.e., crystallinity of LDPE in blends of higher EPDM content. But crystallinity of EPDM is almost same in all unirradiated blends. LE 82 illustrates 85.25 and $21.13 \mathrm{Jg}^{-1}$ heat of fusion i.e., 35.66 and $8.84 \%$ crystallinity for LDPE and EPDM respectively. LE 55 shows 68.94 and $26.78 \mathrm{Jg}^{-1}$ heat of fusion i.e., 28.84 and $11.20 \%$ crystallinity for LDPE and EPDM respectively. While LE 28 blend exhibits the 55.0 and $23.4 \mathrm{Jg}^{-1}$ heat of fusion i.e., 23.01 and $9.79 \%$ crystallinity for LDPE and EPDM respectively. EPDM being amorphous in nature does not encourage crystallization of LDPE while mixed with the later.

Upon exposure to electron beam irradiation, the degree of crystallinity of all LDPE/EPDM blends (for both the phases) decreases with increase of electron beam dose level (Table 2). In LE 82 the crystallinities of LDPE and EPDM come down to 27.26 and $4.28 \%$ after irradiation at $120 \mathrm{kGy}$. For crosslinked (120 kGy) LE 55, the crystallinities of LDPE and EPDM go down to 24.59 and $3.93 \%$. For LE 28, irradiated at $120 \mathrm{kGy}$, the \% crystallinities become 15.12 and $2.79 \%$ for LDPE and EPDM respectively.

It is well known that due to interwoven conformation of polymer chains crosslinking takes place mainly in amorphous zone (Ray Chowdhury et al., 2012a). Once in amorphous phase the crosslinking takes place, the crosslinked phase may shrink. That may reduce the crystallinity rupturing some crystal domains, as common chains are involved in crystalline as well as amorphous phase of polymer. In addition to that due to interaction of crystalline phase with high energy radiation, some crystal domains may be destroyed while crosslink formation, reflecting reduced crystallinity.

The expected trend of reduction in degree of crystallinity has been seen in TMPTA and TAC added LE 82, LE 55 and LE 28 blends. As from the gel content analysis (Fig. 1) we have seen that for TMPTA and TAC added samples the degree of crosslinking is more, TMPTA having an edge over TAC. Thus, due to increased degree of crosslinking the effect of radiation dose on the crystallinity should be higher in presence of TMPTA and TAC. That's why it is obvious from Table 2 and Fig. 2a to $4 a$ that the degree of crystallinity for TMPTA and TAC containing sample are considerably lesser than that of crosslinked blends without crosslinking agents. The reduction of crystallinity for TMPTA containing sample is more than TAC containing ones. That is certainly due to higher degree of crosslinking in presence of TMPTA.

\subsection{Thermogravimetric Analysis (TG)}

Thermogravimetric analysis (TG) has been used to study the degradation behavior of unirradiated and EB irradiated LDPE/EPDM blends. The Thermogravimetric analysis (TG) graphs of neat LDPE, neat EPDM and their blends before and after irradiation are depicted in Fig 5a and $\mathbf{b}$ and the results are presented in Table 3. Both unirradiated and irradiated blends show single step degradation (Fig. 5) as the degradation temperature of EPDM and LDPE are very close. 
Bhuwanesh Kumar Sharma et al. / American Journal of Engineering and Applied Sciences 7 (3): 338-352, 2014

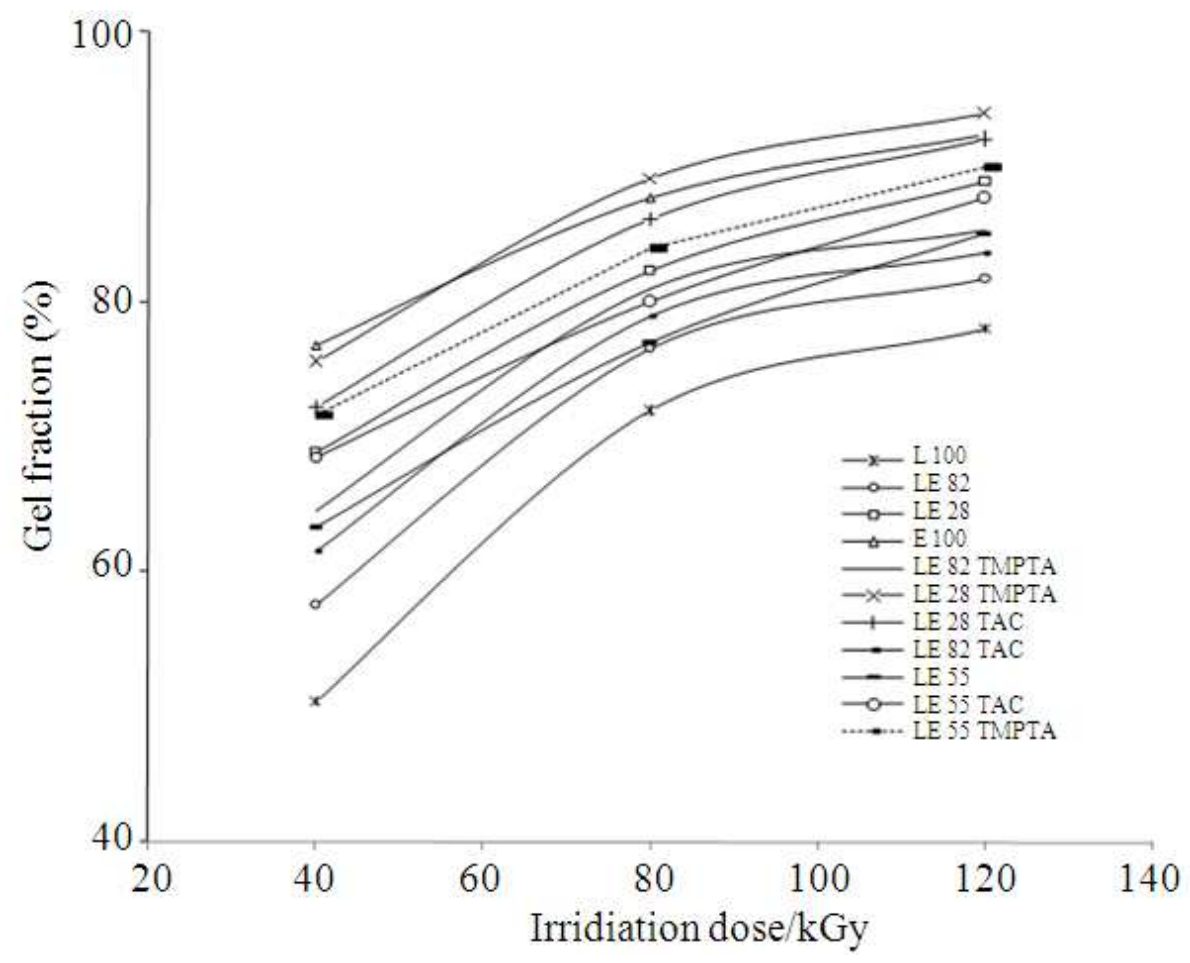

Fig. 1. Variation of gel fractions with blend composition and electron beam irradiation dose

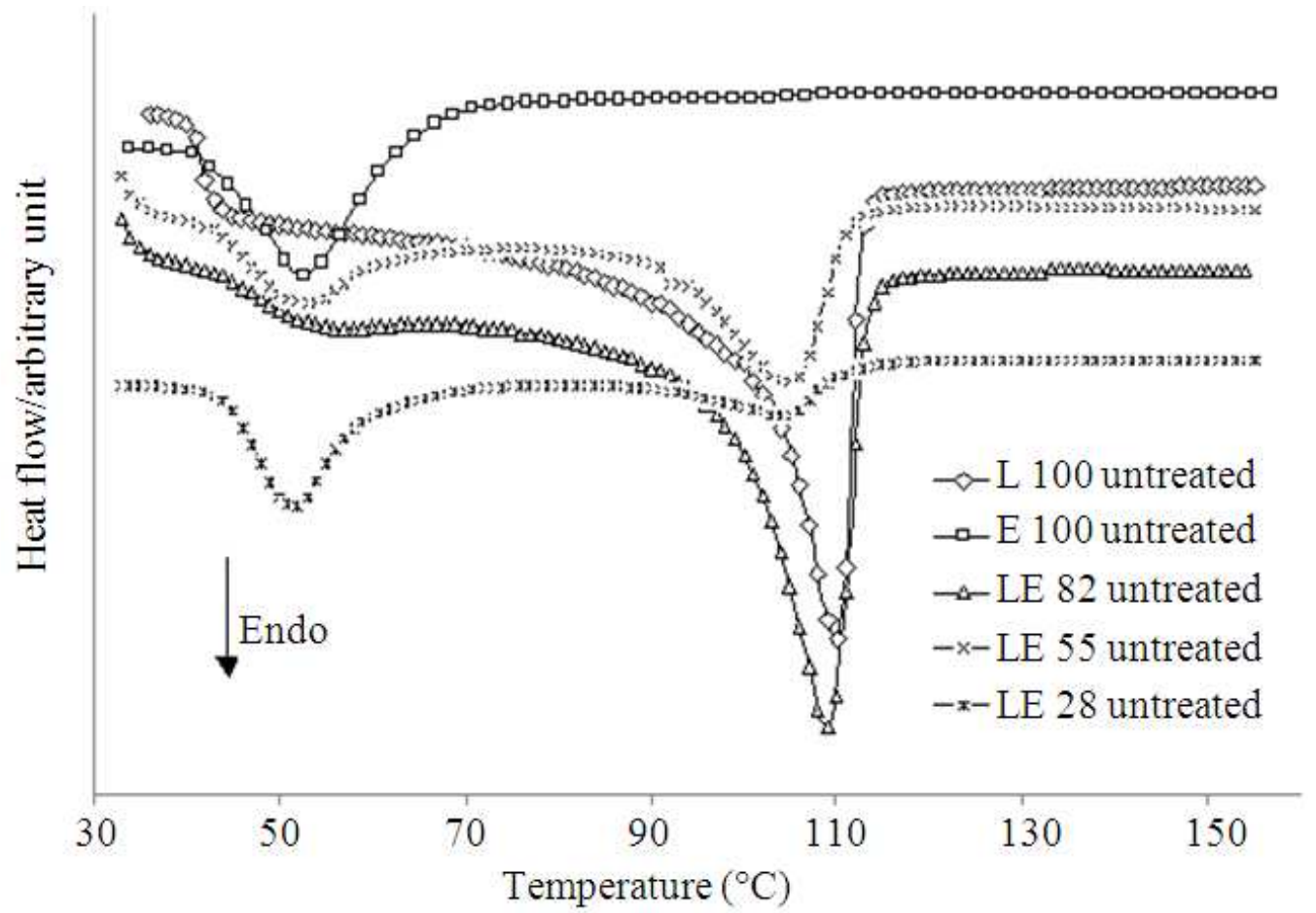

(a) 


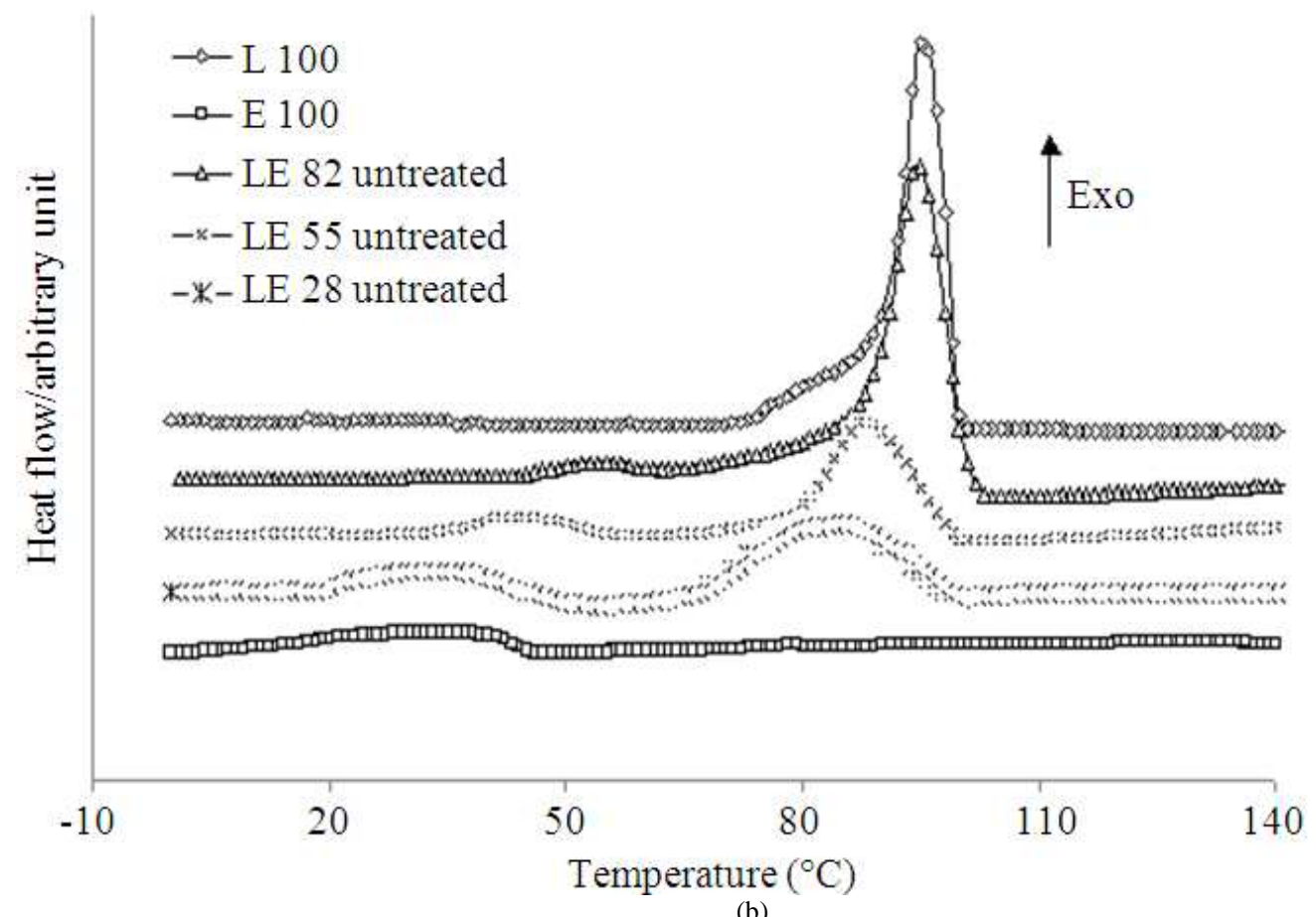

Fig. 2. (a) Effect of blend ratio on the melting behavior (heating mode) of LDPE/EPDM blends. (b) Effect of blend ratio on the crystallization behavior (cooling mode) of LDPE/EPDM blends

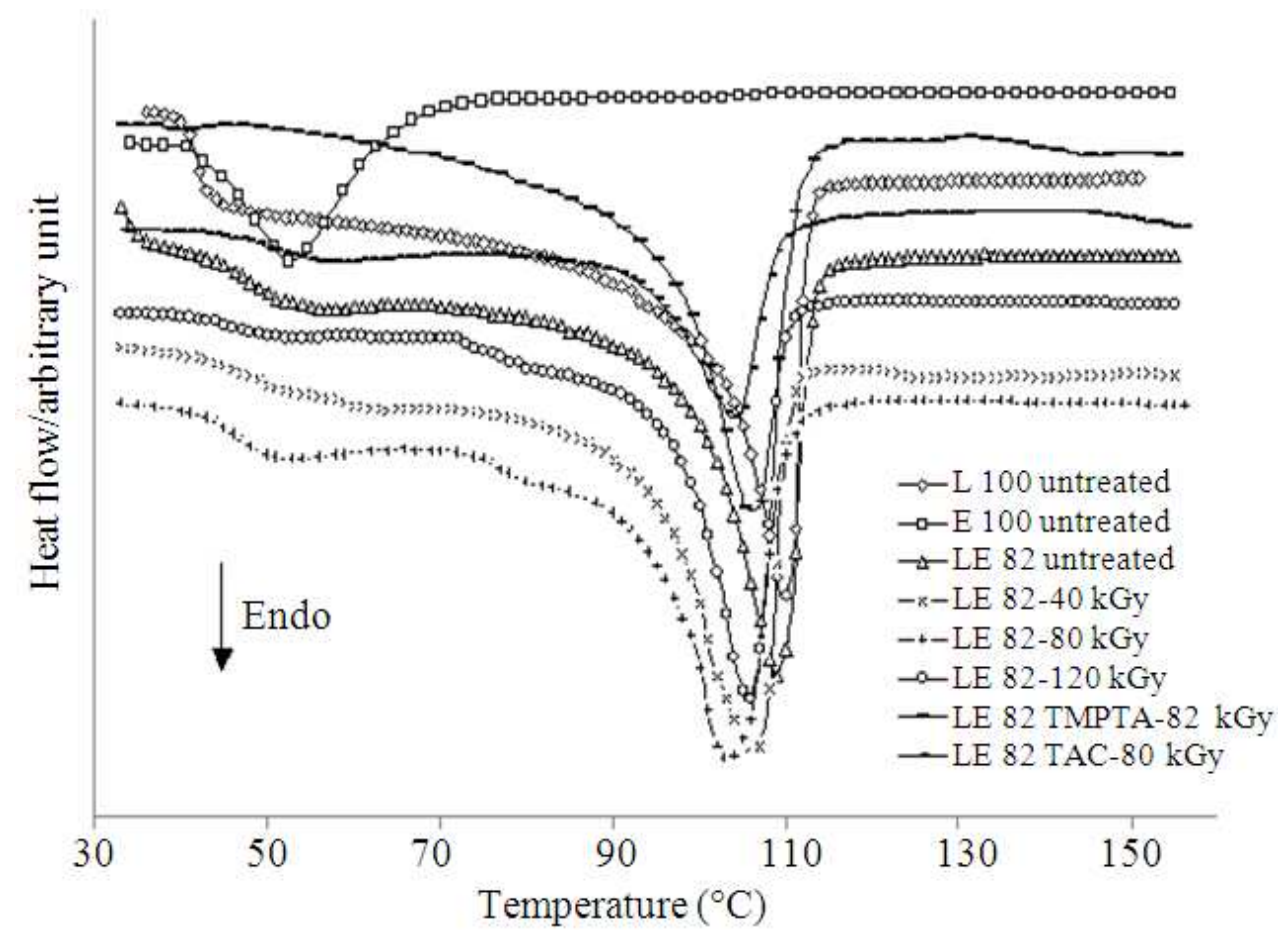

(a) 


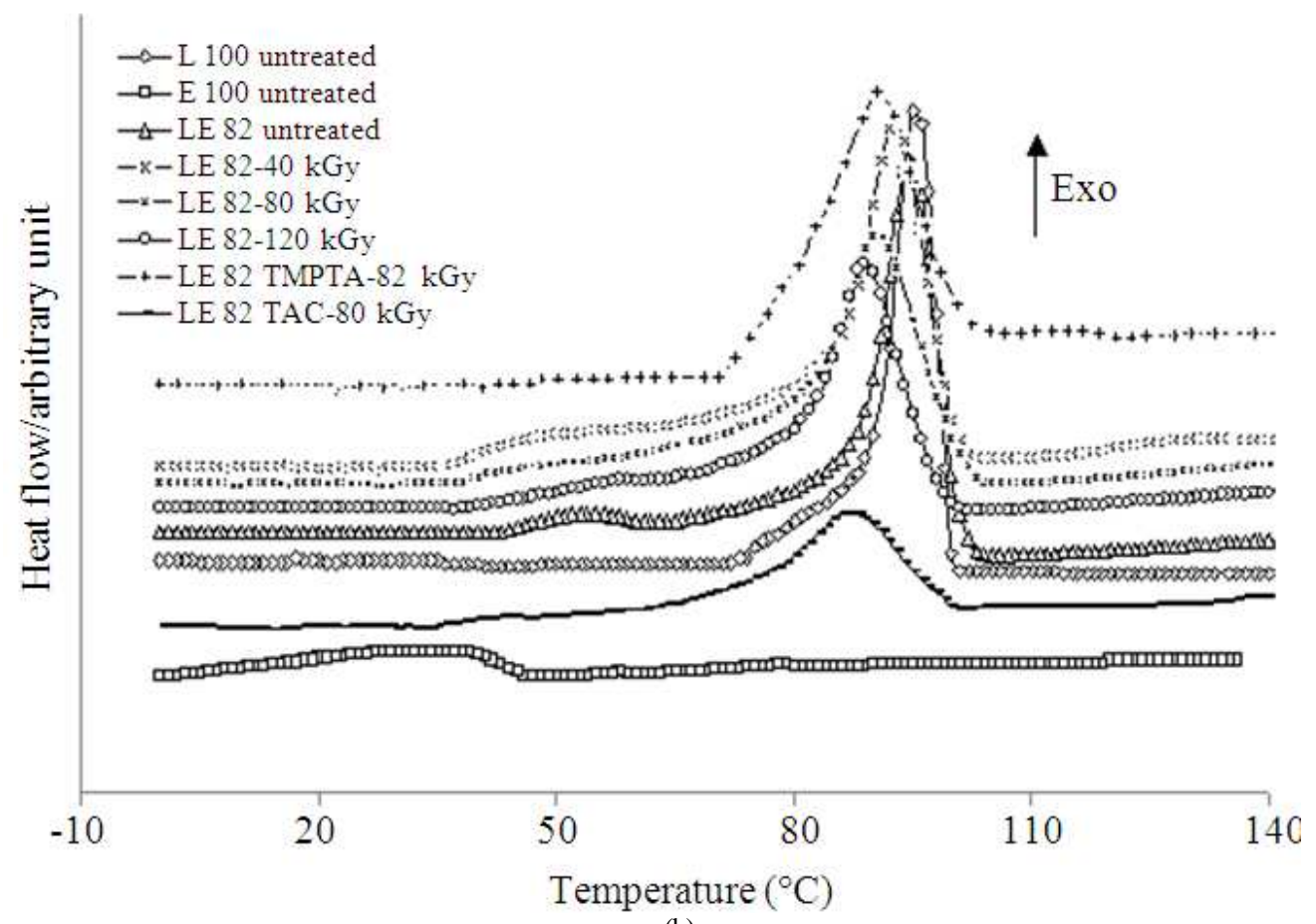

(b)

Fig. 3. (a) Effect of irradiation on the melting behavior (heating mode) of LE 82 blends. (b) Effect of irradiation on the crystallization behavior (cooling mode) of LE 82 blends

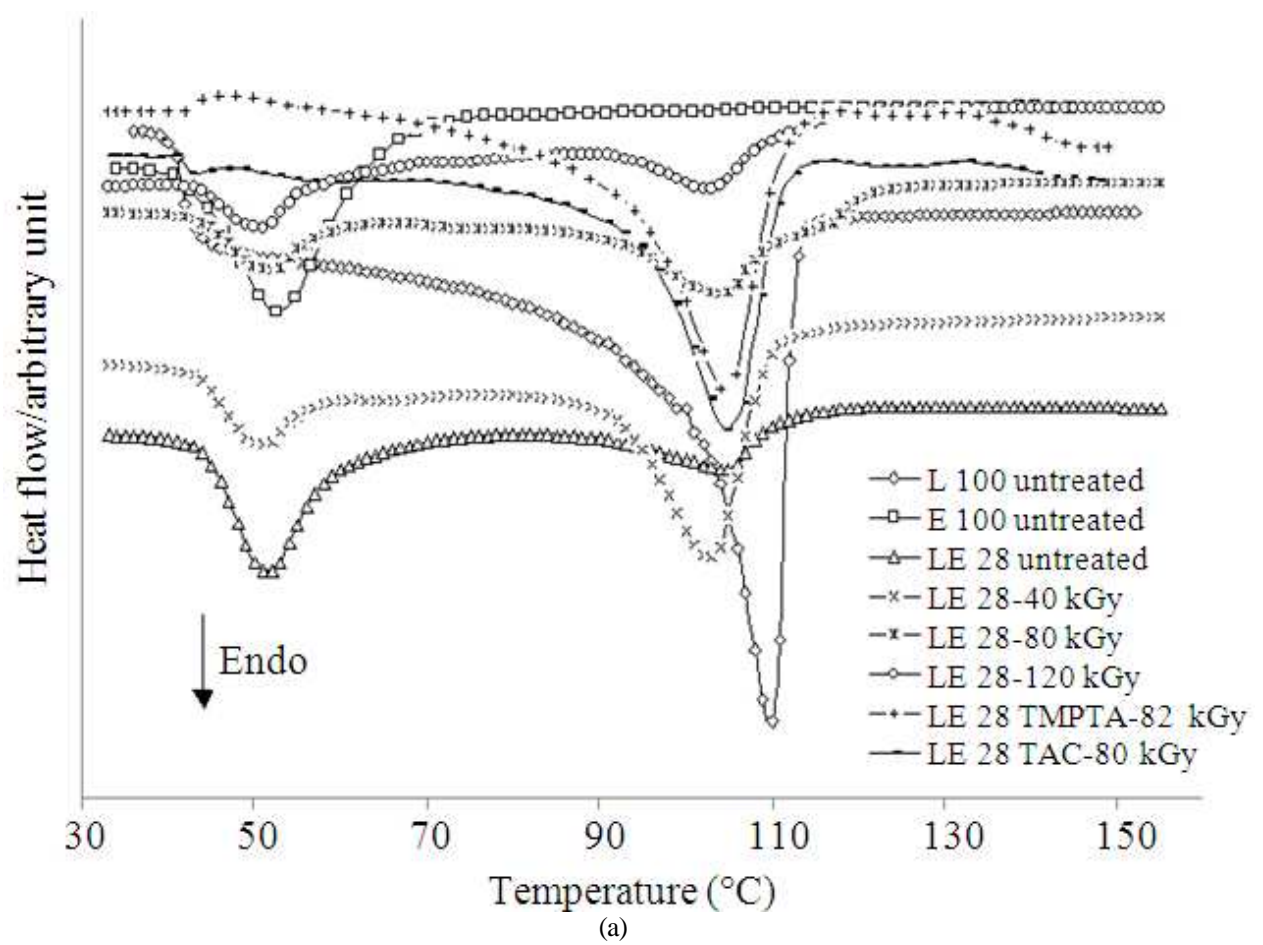


Bhuwanesh Kumar Sharma et al. / American Journal of Engineering and Applied Sciences 7 (3): 338-352, 2014

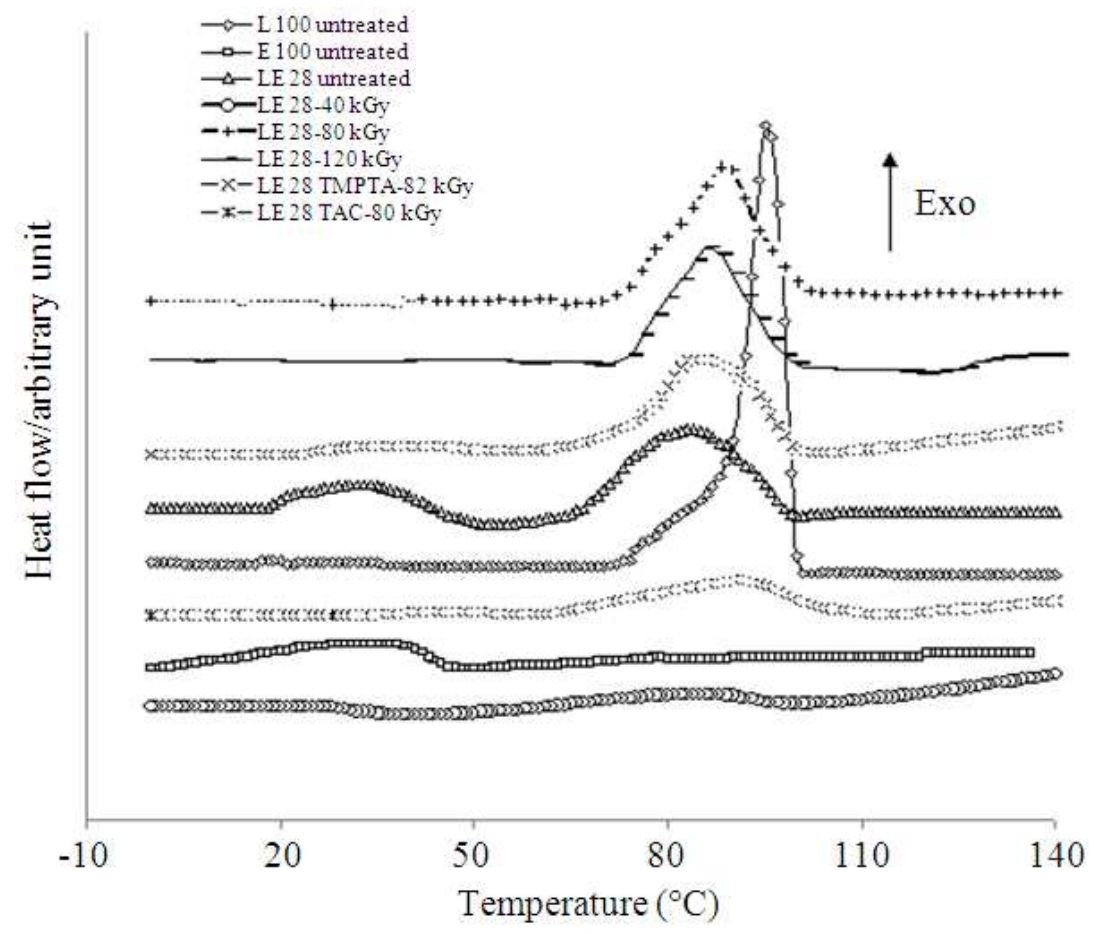

(b)

Fig. 4. (a) Effect of irradiation on the melting behavior (heating mode) of LE 28 blends. (b) Effect of irradiation on the crystallization behavior (cooling mode) of LE 28 blends

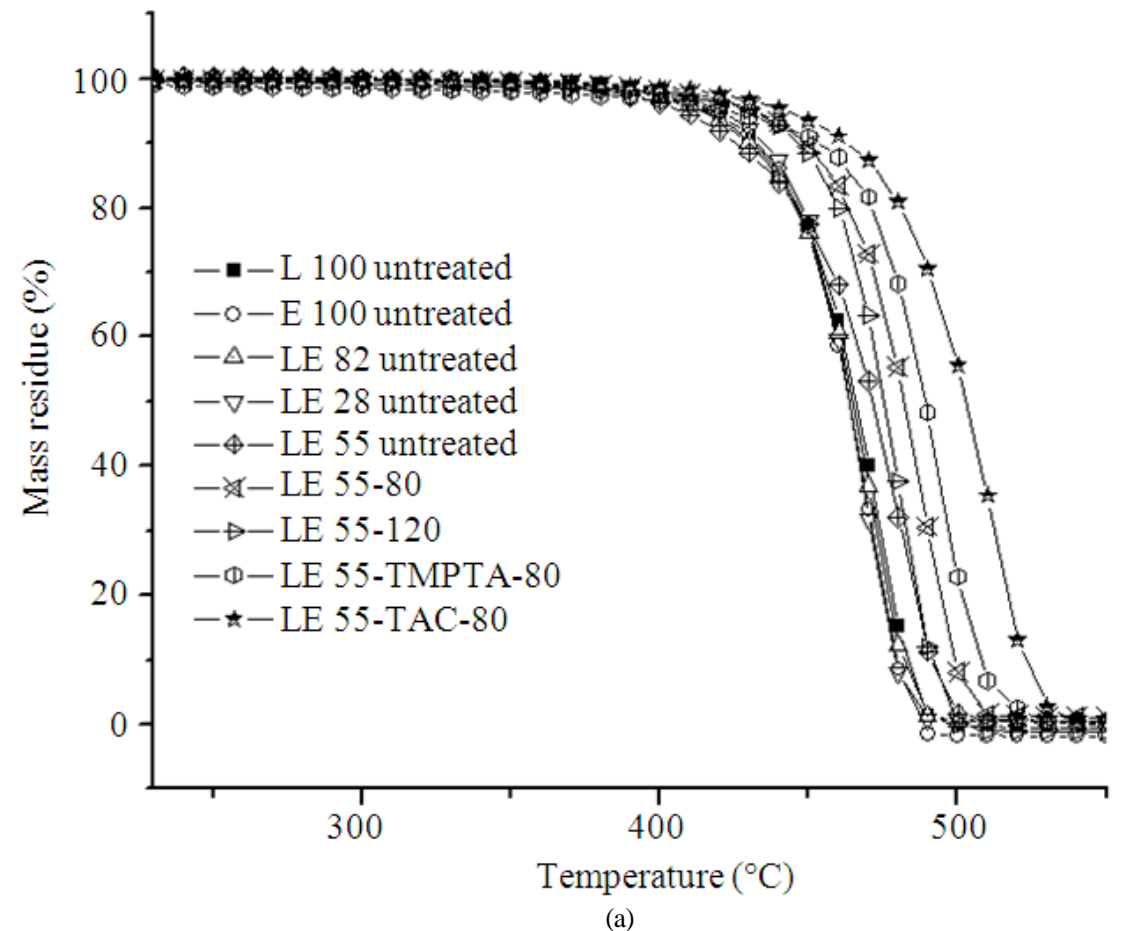

(a) 


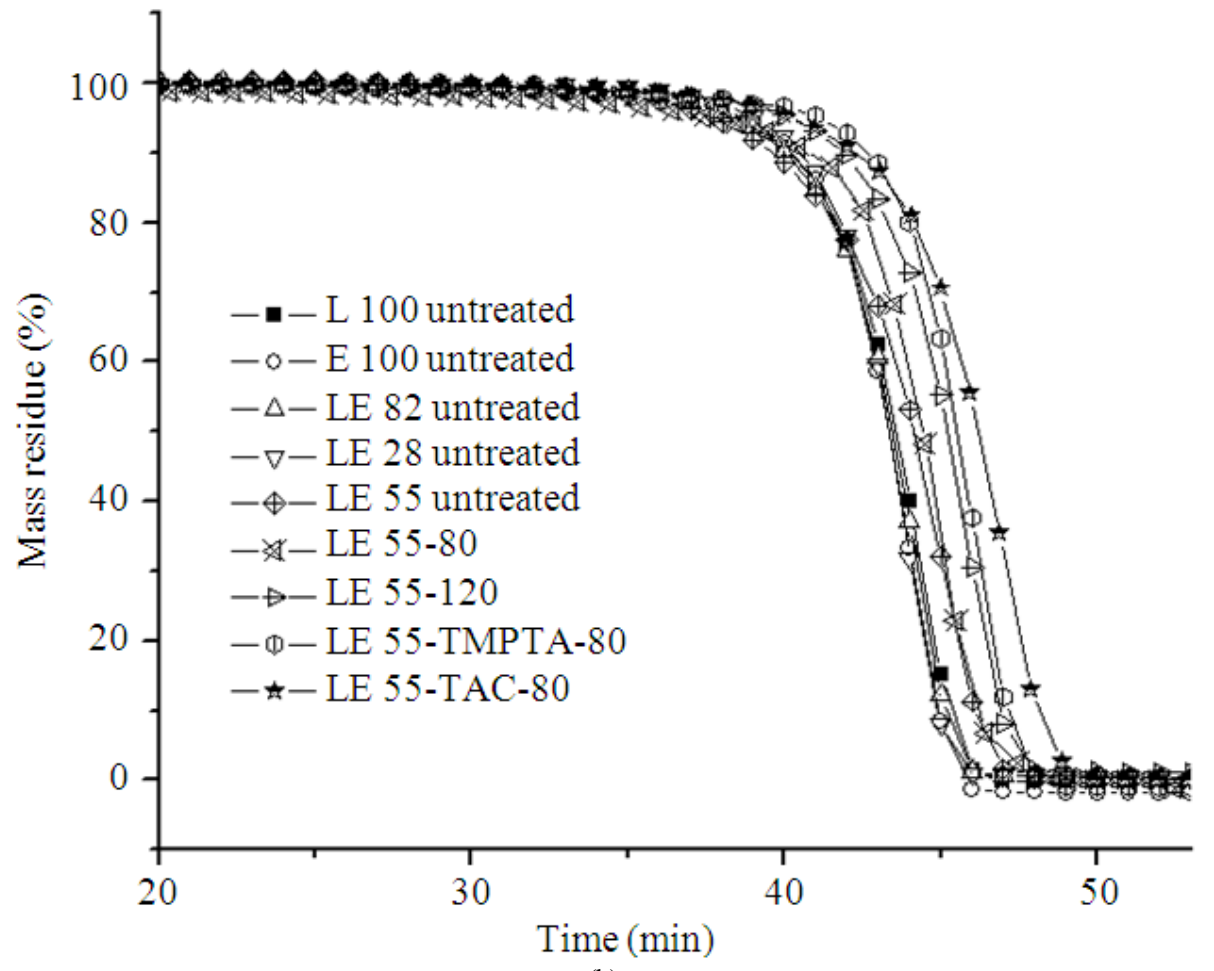

(b)

Fig. 5. (a) TG: Change of mass of LDPE/EPDM blends before and after irradiation with temperature. (b) TG: Change of mass of LDPE/EPDM blends before and after irradiation with time

Table 2. DSC parameters

\begin{tabular}{|c|c|c|c|c|c|c|c|c|}
\hline \multirow[b]{2}{*}{ Samples } & \multicolumn{2}{|l|}{$\mathrm{Tm} /{ }^{\circ} \mathrm{C}$} & \multicolumn{2}{|l|}{$\mathrm{Tc} /{ }^{\circ} \mathrm{C}$} & \multicolumn{2}{|c|}{$\Delta \mathrm{Hm} / \mathrm{Jg}^{-1}$} & \multicolumn{2}{|c|}{$\%$ Crystallinity/Xc } \\
\hline & LDPE & EPDM & LDPE & EPDM & LDPE & EPDM & LDPE & EPDM \\
\hline LDPE & 110.03 & - & 95.030 & 83.010 & - & 34.73 & - & \\
\hline EPDM & - & 52.62 & - & 32.000 & - & 25.79 & - & 10.79 \\
\hline LE 82 untreated & 109.01 & 52.14 & 94.680 & 50.000 & 85.25 & 21.13 & 35.66 & 8.84 \\
\hline LE82-40 kGy & 106.01 & 53.02 & 93.010 & 48.020 & 78.42 & 16.21 & 32.81 & 6.86 \\
\hline LE82-80 kGy & 104.61 & 51.40 & 90.000 & 44.000 & 66.17 & 14.25 & 27.68 & 5.96 \\
\hline LE82-120 kGy & 106.01 & 49.01 & 89.000 & 46.000 & 65.17 & 10.25 & 27.26 & 4.28 \\
\hline LE82 TMPTA-80 kGy & 105.27 & - & 91.340 & - & 39.01 & - & 16.32 & - \\
\hline LE82 TAC-80 kGy & 104.01 & 53.00 & 87.010 & 45.000 & 58.88 & 9.90 & 24.64 & 4.14 \\
\hline LE 55 untreated & 105.00 & 54.00 & 88.030 & 43.000 & 68.94 & 26.78 & 28.84 & 11.20 \\
\hline LE 55-40 kGy & 104.01 & 52.01 & 89.050 & 45.020 & 71.48 & 12.74 & 29.61 & 5.33 \\
\hline LE 55-80 kGy & 103.02 & 51.06 & 85.020 & - & 62.96 & 11.16 & 26.34 & 4.67 \\
\hline LE 55-120 kGy & 102.31 & 49.02 & 79.130 & - & 58.78 & 9.38 & 24.59 & 3.93 \\
\hline LE 55 TMPTA-80 kGy & 104.35 & 52.54 & 83.310 & - & 51.30 & 4.70 & 21.46 & 1.96 \\
\hline LE 55 TAC-80 kGy & 105.52 & 51.79 & 84.020 & - & 59.00 & 7.32 & 24.68 & 3.06 \\
\hline LE 28 untreated & 104.22 & 51.94 & 84.120 & 36.100 & 55.00 & 23.40 & 23.01 & 9.79 \\
\hline LE28-40 kGy & 103.08 & 51.35 & 85.000 & - & 49.25 & 9.17 & 20.60 & 3.83 \\
\hline LE28-80 kGy & 105.02 & 52.13 & 89.700 & - & 39.20 & 7.88 & 16.40 & 3.30 \\
\hline LE28-120 kGy & 103.03 & 50.80 & 86.010 & - & 36.15 & 6.67 & 15.12 & 2.79 \\
\hline LE28 TMPTA-80 kGy & 104.92 & 52.93 & 88.410 & - & 24.85 & 7.33 & 10.39 & 2.45 \\
\hline LE28 TAC-80 kGy & 105.40 & 54.47 & 86.810 & - & 32.90 & 5.86 & 13.76 & 3.07 \\
\hline
\end{tabular}


Table 3. TG parameters

\begin{tabular}{llllllc}
\hline Sample code & $\begin{array}{l}\text { Onset } \\
\text { temperature } \\
\left(\mathrm{T}_{\mathrm{i}}{ }^{\circ} \mathrm{C}\right)\end{array}$ & $\begin{array}{l}\text { Degradation } \\
\text { temperature } \\
\left(\mathrm{T}_{\mathrm{d}}{ }^{\circ} \mathrm{C}\right)\end{array}$ & $\begin{array}{l}\text { Temperature } \\
\text { corresponding to } \\
30 \% \text { mass loss }\left(\mathrm{T}_{30}{ }^{\circ} \mathrm{C}\right)\end{array}$ & $\begin{array}{l}\text { Temperature } \\
\text { corresponding to } \\
50 \% \text { mass loss }\left(\mathrm{T}_{50} /{ }^{\circ} \mathrm{C}\right)\end{array}$ & $\begin{array}{l}\text { Temperature } \\
\text { corresponding to } \\
90 \% \text { ass loss }\left(\mathrm{T}_{90} /{ }^{\circ} \mathrm{C}\right)\end{array}$ & $\begin{array}{l}\text { Activation } \\
\text { energy, } \\
\left(\mathrm{E} / \mathrm{kJmol}^{-1}\right)\end{array}$ \\
\hline L 100 untreated & 370 & 430 & 455 & 465 & 480 & 270.00 \\
E 100 untreated & 380 & 440 & 460 & 470 & 490 & 333.04 \\
LE 82 untreated & 370 & 431 & 454 & 463 & 482 & 297.24 \\
LE 28 untreated & 390 & 442 & 459 & 466 & 480 & 324.34 \\
LE 55 untreated & 368 & 448 & 459 & 471 & 489 & 345.28 \\
LE 55-80 & 379 & 457 & 475 & 480 & 498 & 376.00 \\
LE 55 -120 & 330 & 460 & 465 & 480 & 508 & 432.66 \\
LE 55-TMPTA-80 & 380 & 473 & 476 & 593 & 528 & 458.05 \\
LE 55-TAC-80 & 388 & 488 & 491 & 505 & & 458.76 \\
\hline
\end{tabular}

The Table 3 shows onset temperature $\left(T_{i}\right.$, temperature corresponding to $1 \%$ mass loss), degradation temperature $\left(T_{d}\right)$ and temperatures corresponding to 30,50 and $90 \%$ mass loss $\left(T_{30}, T_{50}\right.$ and $\left.T_{90}\right)$. Neat LDPE shows degradation at $430^{\circ} \mathrm{C}\left(T_{d}\right)$, whereas neat EPDM shows degradation at $440^{\circ} \mathrm{C}$ (Table 3). The higher degradation temperature of EPDM indicates its higher thermal stability than LDPE. Same trend is noticed for $T_{i}$ of LDPE and EPDM also i.e., LDPE starts degradation earlier $\left(370^{\circ} \mathrm{C}\right)$ than $\operatorname{EPDM}\left(380^{\circ} \mathrm{C}\right)$. Interestingly, $T_{30}$, $T_{50}$ and $T_{90}$ of EPDM are also found higher than those of LDPE. The $T_{i}, T_{d}$ and speed of degradations $\left(T_{30}, T_{50}\right.$ and $T_{90}$ ) depend on structural factors, such as molecular structure, crystalline structure and degree of crystallinity. In this case though amount of crystallinity of LDPE is higher than that of EPDM, but due to presence of aliphatic cyclic ring in EPDM molecule, thermal stability becomes higher for EPDM (Barra et al., 1999).

Thermal Degradation temperatures (Td) for blends increase with increase in EPDM content. Interestingly, for LE 55, $T_{d}$ and $T_{90}$ are higher than those of LE 82 and LE 28. Though, no appreciable change is observed for $T_{i}, T_{30}$ and $T_{50}$.

Blend composition is an important decisive factor for degree of compatibility and morphology of blends (Jose et al., 2008). Due to equal proportion of two polymers the degree of compatibility may be higher than LE28 and LE 82 or the generated morphology is such that can discourage thermal degradation.

For LE 82 and LE 55, Tis are almost same but for LE 28 , Ti increases to $390^{\circ} \mathrm{C}$. This is due to presence of more thermally stable EPDM in higher proportion.

However, electron beam irradiation of polymer may promote or demote the thermal stability by interchain crosslinking or degradation. We have investigated here the influence of electron beam irradiation on the thermal stability of LE55 blends in absence and presence of TMPTA and TAC, two widely used crosslinkers.
Ti of LE 55-80 (LE55 irradiated at $80 \mathrm{kGy}$ as denoted in Table 1) appears at $379^{\circ} \mathrm{C}$, where as for unirradiated LE55, $T_{i}$ occurs at $368^{\circ} \mathrm{C}$. Again, Td of LE55 increases by $12^{\circ} \mathrm{C}$ after irradiation at $80 \mathrm{kGy}$ (Table 3). On the other hand, $T_{30}, T_{50}$ and $T_{90}$ of LE55 also increase by 17, 9 and $7{ }^{\circ} \mathrm{C}$ respectively after irradiation. But at higher dose $(120 \mathrm{kGy}) \mathrm{Ti}$ of LE55 goes down to $330^{\circ} \mathrm{C}\left(T_{i}\right.$ of LE55 is $368^{\circ} \mathrm{C}$ ). Also from the $T_{d}, T_{30}, T_{50}$ and $T_{90}$ values it is obvious that the changes are not expected as compared to sample irradiated at $80 \mathrm{kGy}$ (Table 3). This may be due to two reasons. It is well known that during high energy irradiation, degradation and crosslinking of polymer occur simultaneously at different speeds and resultant effect is obtained. One reason may be occurrence of high degree of polymer chain scission along with crosslinking at higher dose (120 kGy). The other possibility is that as the degree of crosslinking is very high, so samples are under internal stress, which leads to less thermal stability. Second explanation is more acceptable as gel content results hint no degradation of polymer chains while irradiating at higher dose (Fig. 1).

Again irradiation at $80 \mathrm{kGy}$ (LE55-80), in presence of TMPTA and TAC promotes the thermal stability of LE55 remarkably. In presence of TMPTA and TAC the degree of crosslinking is more as seen in Fig. 1. Due to the high degree of crosslinking TMPTA and TAC containing samples are more thermally stable than without one. Interestingly, TAC containing LE55 shows more thermal stability than TMPTA containing LE 55 at $80 \mathrm{kGy} . T_{i}, T_{d}, T_{30}, T_{50}$ and $T_{90}$ all of LE55-TAC-80 is higher than LE55-TMPTA-80, though degree of cross linking of TMPTA containing sample is more than TAC containing sample. It is apparently controversial but due to presence of aromatic hexagonal moiety in Tri Allyl Cynuerate (TAC), heat resistant of TAC is higher than aliphatic Trimethyl Propane Triacrylate 
(TMPTA) (Makuuchi and Cheng, 2012). Thus thermal stability of TAC containing sample is higher as it has become a part of the crosslinked network structure of polymer bridging two polymer chains.

To observe the effect of blend composition and electron beam irradiation on the activation Energy (E), Coats-Redfern integral method as mentioned in experimental part has been used. These results are tabulated in Table 3. The E of pure LDPE (L-100) and EPDM (E-100) are found to be 270.81 and 333.04 $\mathrm{kJmole}^{-1}$ respectively before irradiation, which are in agreement with reported values of Ea of LDPE and EPDM (Kayacan and Doğan, 2008; Abadir, 2013). From Table 3, it is noticed that for LE 82 and LE28, E are found to be 297.24 and $324.34 \mathrm{kJmole}^{-1}$, thus with increasing EPDM content thermal degradation of the blend is discouraged obviously due to higher inertness of EPDM towards degradation. For LE55, the E is even more than E of LE28 like $T_{i}, T_{d}, T_{30}, T_{50}$ and $T_{90}$ due to same reason, the effect of blend composition as discussed above. Upon irradiation at $80 \mathrm{kGy}$, E of LE55 increases remarkably (E of LE55 at $80 \mathrm{kGy}$ is 376.43 $\mathrm{kJmole}^{-1}$ ). E of LE55 further is increased in presence of crosslinkers (E for LE55-TMPTA-80 and LE55-TAC-80 are 410.05 and $458.02 \mathrm{kJmole}^{-1}$ ) due to higher degree of crosslinking. TAC containing samples, due to having aromatic unit in molecular structure and involvement of the later in crosslinking, show higher Ea than TMPTA containing samples.

For LE55-120, E is reduced compared to LE55 like $T_{i}$ and $T_{d}$. The reason is same as discussed above.

\section{CONCLUSION}

The present research work dealt with the investigation of the effect of blend ratio and EB irradiation on the crystallization and thermal stabilities of LDPE/EPDM blends. Blend composition and EB dose has been found to have significant effect on crystallization as well as thermal stability of the blends. DSC reveals that melting Temperatures of $\left(T_{m}\right)$ of blends are found to remain unchanged by irradiation. The degree of crystallinity and $T_{c}$ has been found to be decreased with increase of EPDM content as well as electron beam radiation dose. Crosslinkers (TMPTA and TAC) further reduce the crystallinity $\left(X_{c}\right)$ in irradiated blends. Thermal stability of blends (with respect to $T_{i}, T_{d}$, $T_{30}, T_{50}, T_{90}$ and E) is enhanced with increase in the proportions of EPDM in the blends as well as electron beam irradiation. In presence of TMPTA and TAC, due to higher degree of crosslinking the effect is more on the above mentioned properties. Due to presence of aromatic moiety in TAC, TAC containing blends are thermally more stable than TMPTA containing blends. At higher dose $(120 \mathrm{kGy})$ chain scission takes place reducing the effect of crosslinking on the properties.

\section{Appendix}

Calculation of activation energy of degradation by integral method of Coats and Redfurn.

\section{Theory}

The fractional degradation of polymeric material can be expressed in terms of mass change by the following Equation 3:

$\alpha=\frac{w_{0}-w}{w_{0}-w_{\infty}}$

where, $w_{o}, w$ and $w_{\infty}$, are the initial, at any instant during thermal analysis and final mass of the samples, respectively.

Rate of degradation can be expressed in order based reaction kinetics and it can be written as:

$-\frac{d \alpha}{d t}=k(1-\alpha)^{n}$

The rate of reaction is proportional to the nth power of un-reacted part of the sample. The power $n$ is considered as the order of the reaction and $\mathrm{k}$ is reaction rate constant. But this rate constant is a function of temperature which can be expressed by Arrhenius Equation:

$k=A e^{-E / R T}$

where, $E$ is the activation energy of the reaction. Substituting k from Equation 5 into Equation 4 results the following Equation:

$-\frac{d \alpha}{d t}=A e^{-E / R T}(1-\alpha)^{n}$

After separating the variables from Equation 6 the following Equation can be obtained Equation 7 and 8:

$$
-\frac{d \alpha}{(1-\alpha)^{n}}=A e^{-E / R T} d t
$$




$$
\text { The rate of heating } \beta=\frac{d T}{d t}
$$

Or:

$d t=\frac{d T}{\beta}$

Putting the expression of $d t$ in Equation 7 and integrating between limits $T_{1}$ and $T_{2}$ Equation 9:

$$
-\int_{0}^{\alpha} \frac{d \alpha}{(1-\alpha)^{n}}=\frac{A}{\beta} \int_{T_{1}}^{T_{2}} e^{-\frac{E}{R T}} d T
$$

But the integral at the right side ${ }_{T 1}{ }^{T 2} e^{-E / R T} d T$ has no analytical solution. Therefore several approximate solutions of the equations have been given in literature (Coats and Redfern, 1964; Baloch et al., 2011; Flynn and Wall, 1966; Kissinger, 1957).

But in our investigation, the solution given by (Coats and Redfren, 1964; Baloch et al., 2011) has been used to determine the activation energy of the degradation reaction. The approximate solution of the integral as per this method is like the following:

$\operatorname{In}\left[\frac{-\operatorname{In}(1-\alpha)}{T^{2}}\right]-\operatorname{In}\left[\frac{A R}{\beta E}\left(1-\frac{2 R T}{E}\right)\right]-\frac{E}{R T}($ for $n=1)$

Integral as per this method is like the following. And Equation 11:

$$
\begin{aligned}
& \operatorname{In}\left[-\operatorname{In}\left\{\frac{1-(1-\alpha)^{n}}{(1-n)^{T^{2}}}\right\}\right]=\operatorname{In}\left[\frac{A R}{\beta E}\left(1-\frac{2 R T}{E}\right)\right] \\
& -\frac{E}{R T}(\text { for } n \neq 1)
\end{aligned}
$$

Thermal degradation of LDPE and EPDM is considered as first-order reaction as (Kayacan and Doğan, 2008) reported it as first order from the reasonable data fit to straight lines (Kayacan and Doğan, 2008). Thus Equation 10 has been considered for our system.

As $2 R T / E$ is much lower than unity then a plot of $\ln [-$ In (1- $\alpha) / T^{2}$ ] against $1 / T$ from Equation 10 should give a straight line. From the slope of that line the activation Energy (E) was calculated.

\section{REFERENCES}

Abadir, E.F., 2013. Mechanism and kinetics of the nonisothermal degradation of Ethylenepropylene Diene Monomer (EPDM). J. Therm. Anal. Cal., 114: 14091413. DOI: 10.1007/s10973-009-0308-9

Abdel-Aziz, M.M., E.M. Abdel-Bary, M.M. Abou Zaid and A.A. El Miligy, 1992. Effect of gamma radiation on EPDM/LDPE blends. J. Elast. Plast., 24: 178-191. DOI: 10.1177/009524439202400303

Airinei, A., D.M. Stelescu, M. Homocianu, N. Fifere and M. Aflori et al., 2013. Structural characteristics of some high density polyethylene/EPDM blends. Polym. Test., 32: 187-196.

DOI: 10.1016/j.polymertesting.2012.10.010

Baloch, M.K., M.J.Z. Khurram and G. Durrani, 2011. Application of different methods for the thermogravimetric analysis of polyethylene samples. J. Applied Polym. Sci., 120: 3511-3518. DOI: 10.1002/app.33538

Barra, G.M.O., J.S. Crespo, J.R. Bertolino, V. Soldi and A.T. Nunes Pires, 1999. Maleic anhydride grafting on EPDM: Qualitative and quantitative determination. J. Braz. Chem. Society, 10: 31-34. DOI: 10.1590/S0103-50531999000100006

Britton, J.E., F.D. Metcalf, J.G. Sommer and T.H. Kuan, 1978. Polyethylene EPDM Compositions. US Patents, 128: 523-523.

Charlesby, A., 1954. Gel formation and molecular weight distribution in long-chain polymers. Proceedings of the Royal Society of London, Series A, Mar. 23-23, Royal Society, pp: 542-557.

Charlesby, A. and S.H. Pinner, 1959. Analysis of the solubility behaviour of irradiated polyethylene and other polymers. Proc. R. Soc. Lond. A, 249: 367386. DOI: 10.1098/rspa.1959.0030

Chattopadhyay, S., T.K. Chaki and A.K. Bhowmick, 2001. Electron beam modification of thermoplastic elastomeric blends made from polyolefins. J. Mater. Sci., 36: 4323-4330. DOI: 10.1023/A:1017989526538

Cleland, M.R., L.A. Parks and S. Cheng, 2003. Applications for radiation processing of materials. Nucl. Instrum. Methods Phys. Res. Section B: Beam Interactions Mater. Atoms, 208: 66-73. DOI: 10.1016/S0168-583X(03)00655-4 
Coats, A.W. and J.P. Redfern, 1964. Kinetic parameters from thermogravimetric data. Nature, 201: 68-69. DOI: $10.1038 / 201068 \mathrm{a} 0$

Dikland, H.G. and M. Van Duin, 2002. Crosslinking of EPDM Studied with Optical Spectroscopy. In: Spectroscopy of Rubber and Rubbery Materials, Litvinov, V.M. and P.P. De, (Eds.)., Ismithers Rapra Publishing, Shawbury, ISBN-10: 1859575064, pp: 656.

Flynn, J.H. and L.A. Wall, 1966. A quick, direct method for the determination of activation energy from thermogravimetric data. J. Polym. Sci. Part B: Polym. Lett., 4: 323-328. DOI: 10.1002/pol.1966.110040504

Handlos, V., 1979. Enhanced crosslinking of polyethylene. Radiat. Phys. Chem., 14: 721-728. DOI: 10.1016/0146-5724(79)90107-9

Hung, H.D., S.S. Ho and P. Serguei, 2004. Crosslinking and degradation of polypropylene by electron beam irradiation in the presence of trifunctional monomers. Radiat. Phys. Chem., 69: 239-244. DOI: 10.1016/S0969-806X(03)00458-4

Jamal, N.A., H. Anuar and A.R. Shamsul, 2011. Enhancing the mechanical properties of cross-linked rubber-toughened nanocomposites via electron beam irradiation. J. Nanotechnol., 1: 1-8. DOI: 10.1155/2011/769428

Jose, S., S. Thomas, P.K. Biju, P. Koshy and J. KargerKocsis, 2008. Thermal degradation and crystallisation studies of reactively compatibilised polymer blends. Polym. Degradat. Stab., 93: 11761187. DOI: $10.1016 /$ j.polymdegradstab.2008.03.001

Kayacan, I. and O.M. Doğan, 2008. Pyrolysis of low and high density polyethylene. Part I: Non-isothermal pyrolysis kinetics. Energy Sources, Part A: Rec. Utilizat. Environ. Effects, 30: 385-391. DOI: 10.1080/15567030701457079

Kissinger, H.E., 1957. Reaction kinetics in differential thermal analysis. Anal. Chem., 29: 1702-1706. DOI: 10.1021/ac60131a045

Machi, S., 1995. Radiation technology for sustainable development. Radiat. Phys. Chem., 46: 399-410. DOI: 10.1016/0969-806X(95)00183-X

Magida, M.M., 2012. Study of structural and thermal properties of electron beam irradiated polymethylmethacrylate/bisphenol-a-polycarbonate blends. J. Applied Polym. Sci., 125: 3184-3190. DOI: 10.1002/app.36494
Makuuchi, K. and S. Cheng, 2012. Radiation Processing of Polymer Materials and its Industrial Applications. 1st Edn., John Wiley and Sons, Hoboken, ISBN-10: 0470587695, pp: 415.

Maziyar, S., H. Azman and T.R. Chantara, 2012. Electron beam irradiation of low density polyethylene/ethylene vinyl acetate filled with metal hydroxides for wire and cable applications. Polym. Degradat. Stab., 97: 1432-1437. DOI: 10.1016/j.polymdegradstab.2012.05.010

Mohamed, M.A., M.Z.A. Mahmoud, N.A. Shaltout and A.E.M. Ahmed, 2012. Effect of high energy electron beam irradiation on properties of EPDM rubber/high density polyethylene/carbon black composites. Polym. Plast. Tech Eng., 51: 1361-1366. DOI: 10.1080/03602559.2012.702257

Morawiec, J., A. Pawlak, M. Slouf, A. Galeski and N. Krasnikowa et al., 2005. Preparation and properties of compatibilized LDPE/organo-modified montmorillonite nanocomposites. Eur. Polym. J., 41: 1115-1122. DOI: 10.1016/j.eurpolymj.2004.11.011

Morteza, E., M.E. Zeynali, A. Mojtaba and A.H. Abbas, 2009. LDPE/EPDM blends as electrical insulators with unique surface, electrical and mechanical properties. Iran. Polym. J., 18: 37-47.

Mukhopadhyay, P. and C.D. Das, 1990. Effect of E/P ratio on the rheology and morphology of crosslinkable polyethylene and EPDM blends. J. Applied Polym. Sci., 39: 49-62. DOI: 10.1002/app.1990.070390105

Nouri, M. and M. Mehrabzadeh, 1996. Studies on rheological behaviour of LDPE/EPDM blends using a torque rheometer. Iran. Polym. J., 5: 237-241.

Pyun, H.C., Y.C. Lee, K.J. Kim and B.M. Yoon, 1982. Effect of trifunctional monomers and antioxidants on crosslinking reaction of polyethylene. J. Korea Nuclear Society, 14: 70-77.

Ray Chowdhury, S. and S. Sabharwal, 2011. Molecularscale design of a high performance organicinorganic hybrid with the help of gamma radiation. J. Mater. Chem., 21: 6999-7006. DOI: 10.1039/C1JM10943J

Ray Chowdhury, S., J.K. Mishra and C.K. Das, 2000. Shrinkability and microstructural properties of composites based on Low-Density Polyethylene (LDPE) and Polyurethane (PU) rubber. J. Thermoplastic Compt. Mater., 13: 400-416. DOI: 10.1106/V6PP-X3D2-RGDK-FT7P 
Ray Chowdhury, S., S. Sabharwal and K.S.S. Sarma, 2012a. Development of recyclable electron beam radiation crosslinked LDPE/'EVA-embedded nanoclay' Nanocomposites. J. Reinforced Plastics Compt., 31: 1426-1434. DOI: 10.1177/0731684412459247

Ray Chowdhury, S., S.A. Khader and K.S.S. Sarma, $2012 \mathrm{~b}$. Tuning of required mechanical parameters of LDPE/EVA blends for high temperature shape formation, by electron beam irradiation. Antec-Int. Society Plastic Eng. Mumbai India.

Rizk, R.A.M., A.M. Abdul-Kader, Z.I. Ali and M. Ali, 2009. Effect of ion bombardment on the optical properties of LDPE/EPDM polymer blends. Vacuum, 83: 805-808. DOI: 10.1016/j.vacuum.2008.07.012

Sadek, E.M., D.E. El-Nashar and A.M. Motawie, 2003. Modification of ethylene propylene diene terpolymer rubber by some thermoplastic polymers. Polym. Plast. Tech Eng., 42: 627-642. DOI: 10.1081/PPT-120023099

Sam, S.T., H. Ismail, Z. Ahmad and C.T. Ratnam, 2012. Effect of the electron beam irradiation on the properties of Epoxidized Natural Rubber (ENR 50) compatibilized linear low-density polyethylene/soya powder blends. J. Applied Polym. Sci., 124: 52205228. DOI: 10.1002/app.34136

Santra, R.N., A.K. Bhowmick, G.B. Nando and B.K. Samantaray, 1993. In situ compatibilization of lowdensity polyethylene and polydimethylsiloxane rubber blends using ethylene-methyl acrylate copolymer as a chemical compatibilizer. J. Applied Polym. Sci., 49: 1145-1158. DOI: 10.1002/app.1993.070490703
Sen Majumder, P. and A.K. Bhowmick, 2000. Structureproperty relationship of electron-beam-modified EPDM rubber. J. Applied Polym. Sci., 77: 323-337. DOI: $10.1002 /($ SICI) $1097-$ 4628(20000711)77:2<323::AID-APP8>3.0.CO;2-V

Senna, M.M., H.A. Youssef and H.M. Eyssa, 2007. Effect of electron beam irradiation, EPDM and azodicarbonamide on the foam properties of LDPE sheet. Polym. Plastics Tech. Eng., 46: 1093-1101. DOI: $10.1080 / 03602550701525271$

Vranjesn, N. and V. Rek, 2007. Effect of EPDM on Morphology, Mechanical Properties, Crystallization Behavior and Viscoelastic Properties of iPP+HDPE Blends. Macromol. Symp., 258: 90-100. DOI: 10.1002/masy.200751210

Waldron, R.N., H.F. Mcrae and J.D. Madison, 1985. The effects of various monomers on crosslinking efficiency. Radiat. Phys. Chem., 125: 843-848. DOI: 10.1016/0146-5724(85)90165-7

Wang, Q., F. Wang and K. Cheng, 2009. Effect of crosslink density on some properties of electron beam-irradiated styrene-butadiene rubber. Radiat. Phys. Chem., 78: 1001-1005. DOI: 10.1016/j.radphyschem.2009.06.001

Wiedenmann, R., 1977. Thermal-oxidative stability of radiation-crosslinked polyethylene-compounds for wire and cable insulations. Radiat. Phys. Chem., 9: 701-709. DOI: 10.1016/0146-5724(77)90183-2

Zaharescu, T., M. Chipară and M. Postolache, 1999. Radiation processing of polyolefin blendsII. Mechanical properties of EPDM-PP blends. Polym. Degradat. Stab., 66: 5-8. DOI: 10.1016/S01413910(99)00045-2 